\title{
Evaluation of the Size and Location of the Genial Plexus, Related to Age, Sex and Dental Presence, in Implant Surgeries
}

\section{João Henrique Scotti Alérico ${ }^{1}$, Neuza Maria Souza Picorelli Assis' ${ }^{2}$, Carlos Eduardo Francischone ${ }^{3}$, Karina Lopes Devito4, Francisco Antoninho Alérico4, Bruno Salles Sotto-Maior ${ }^{4}$}

${ }^{1}$ Department of Implantology, Sao Leopoldo Mandic Dental Research Center, São Leopoldo, Brazil; ${ }^{2}$ Department of Dental Clinic, Federal University of Juiz de Fora, Juiz de Fora, Brazil; ${ }^{3}$ Department of Diagnosis, Paranaense University, Francisco Beltrão, Brazil; ${ }^{4}$ Department of Restorative Dentistry, Federal University of Juiz de Fora, Juiz de Fora, Brazil

Correspondence to: João Henrique Scotti Alérico, joao_alerico@hotmail.com; Neuza Maria Souza Picorelli Assis, neuzapicorelli@terra.com.br; Carlos Eduardo Francischone, drfrancischone@yahoo.com.br; Karina Lopes Devito, karina.devito@ufjf.edu.br; Francisco Antoninho Alérico, franciscodechico@gmail.com; Bruno Salles Sotto-Maior, brunosottomaior@gmail.com

Keywords: Genial Canal, Cone-Beam Computed Tomography, Dental Implants, Measurement, Paresthesia Received: October 12, $2017 \quad$ Accepted: October 22, $201 \quad$ Published: October 25, 201

Copyright () 2017 by authors and Scientific Research Publishing Inc.

This work is licensed under the Creative Commons Attribution International License (CC BY 4.0).

http://creativecommons.org/licenses/by/4.0/

\section{Open Access}

\section{ABSTRACT}

Generally being considered as a safe area for surgical approaches, the region between the mental foramina presents important anatomical structures. The objective of this study was to measure the dimensions of the genial plexus and its three-dimensional location in CBCT images, correlating the characteristics of this structure with dental presence, sex and age of patients. A total of 149 cone beam computer tomography (CBCT) scans of dentate $(n=74)$ and edentulous patients $(n=75)$ were selected, 59 male and 90 female, aged 18 - 86 years. Measurements of width and length of the genial canal were performed, and the shortest distances of the genial plexus were determined in relation to the alveolar bone crest, the buccal cortical bone and the base of the mandible. The results indicated significant differences between the dentate and edentulous groups for the mandibular canal length ( $p=$ $0.030)$, distance from alveolar crest $(\mathrm{p}<0.001)$, and distance from buccal cortical bone ( $\mathrm{p}<$ 0.001 ), with significantly higher values in dentate patients. As for gender, the distances between the genial plexus and the alveolar bone crest $(p<0.001)$ and the buccal cortical bone ( $p=0.028$ ) were significantly shorter for females. Regarding age, only the distance between the genial plexus and the alveolar crest showed a significant difference $(p<0.001)$, and the smallest values were measured in the older patients. It can be concluded that there are vari- 


\begin{abstract}
ations of the genial plexus in relation to gender, age and between edentulous and dentate patients. Therefore, the anterior region of the mandible, especially the midline should be observed with caution when undergoing surgical procedures, such as removal of bone grafts and installation of dental implants.
\end{abstract}

\title{
1. INTRODUCTION
}

Although the anterior region of the mandible is considered safe as a bone graft donor area and for the installation of dental implants [1,2], some studies have reported accidents and the potential risk of associated complications to surgical interventions in $[3,4]$. Anatomic structures such as the incisive canal and the genial plexus $[5,6]$ are main responsible for these complications.

Moreover, the distance of these structures to bone cortices tends to decrease by the influence of factors such as age, edentulism and the sex of the individuals, increasing the chance of trans- and post-operative complications.

The incisive canal and the genial plexus contain terminal branches of nerves and blood vessels that feed the teeth of the intermental region, the intraosseous space and the vestibular gingiva of the symphysis region $[7,8]$. Being described as an extension of the mandibular canal, the incisive canal begins its course in the mental foramina, traversing the anterior region of the mandible to the central incisive region in a descending way. Radiographically, it is well-defined up to the region of lateral incisors [9], and in the region of central incisors, the canal image becomes diffuse [7]. In addition to anastomoses [10], the presence of another anatomical accident called the genial plexus [11] or upper and lower genial foramen [3], or also lingual foramen which jointly contributes to the crossed neurovascularization at the level of the mandibular midline $[3,9]$.

It was discovered by magnetic resonance imaging and dissection of anatomical parts that the content of the genial plexus is of neurovascular nature $[3,12]$. This may be due to reports of cases of hemorrhage, hematomas $[13,14]$ and/or sensory disturbances after surgical procedures in the anterior region of the mandible [15-18], and can also lead to dysesthesia [19,20], in addition to cases of indirect surgical trauma associated with hematomas.

Cone-beam computed tomography (CBCT), which is the method of choice in the diagnosis and surgical planning for removal of bone grafts and installation of dentalimplants [21], provides the possibility of performing accurate bone measurements of the existing anatomy [22, 23], including small structures such as the incisive canal and the genial plexus $[13,24,25]$. Precision in surgical planning reduces the possibility of injury to patients and surrounding anatomical structures. Thus, the objective of this study was to evaluate the dimensions of the genial plexus and its three-dimensional location in CBCT images, correlating the characteristics of this structure with dental presence, sex and age of patients.

\section{MATERIAL AND METHODS}

This retrospective cross-sectional study was conducted in full compliance with the World Medical Association's Declaration of Helsinki and was approved by the ethics committee in research of Centro de Pesquisas Odontológicas São Leopoldo Mandic (No. 1.517.140).

A total of 950 consecutive CBCT exams of the mandible region were evaluated, belonging to the database of Clínica Radiológica de Francisco Beltrão (Paraná, Brazil). A total of 149 CBCT exams were stratified for dental presence (totally toothed or totally edentulous), sex (female and male) and age (18 to 30 years, 31 to 60 years and $\geq 61$ years) (Table 1 ).

Inclusion criteria were patients aged 18 years and over, of both sexes, with all teeth present or all absent, who did not present metallic artifacts in the tomographic images. Exams that presented osseointegrated implants, cast metal cores, prosthetic crowns, or the presence of impacted teeth, bone pathologies and dentate patients with periodontal bone loss were excluded from the sample. 
Table 1. Distribution of the sample regarding sex, dental presence, and average age.

\begin{tabular}{ccc}
\hline Age & \multicolumn{2}{c}{$52.2 \pm 15.7$ anos } \\
\hline \multirow{2}{*}{ Genre } & Male & $59(39.6 \%)$ \\
& Female & $90(60.4 \%)$ \\
Dentition & Dentate & $74(49.66 \%)$ \\
& Edentulous & $75(50.3 \%)$ \\
\hline
\end{tabular}

Source Author: Own Authorshi.

The exams were acquired using the I-cat 3D Imaging System Classical (Imaging Sciences International, Hatfield, PA, USA), using the following exposure parameters: $36.15 \mathrm{mAs}$ and $120 \mathrm{kVs}$ with a rotation time of 40 seconds using $0.2 \mathrm{~mm}$ of isotropic voxel. Scans were performed by a team of trained technicians, maintaining the patient's occlusal plane parallel to the horizontal plane and the median sagittal plane perpendicular to the ground. The analysis of the measurements was performed by a dental surgeon, specialist in Dental Radiology, in a room with adequate lighting, using the Xoran Cat ${ }^{\circledast}$ software (Imaging Sciences International, Hatfield, Pennsylvania, USA).

To select the area of interest, the distance between the mesial extremity of each mental foramen was measured, and half of this distance guided the average tomographic image. From this section, five parasagittal tomographic sections were evaluated for each side. The section that presented the greatest clarity of the genial plexus was chosen to perform the measurements (Figure 1(A)).

The following measurements were performed: longest width of the genial canal (W) or (D); longest length of the genial canal in relation to the alveolar bone crest (L) or (L1); (D1) or (L2), which was performed between the uppermost portion of the genial plexus and the alveolar bone crest (for dentate patients the reference was the buccal bone crest); shortest distance from the genial plexus to the buccal cortical bone (D2) or (L3), which was performed between the most vestibular portion of the genial plexus and the buccal cortical bone; (D3) or (L4), which was performed between the lowest portion of the genial plexus and the cortical part of the mandible base (Figures 1(B)-(D)).

Figure 2(A) is the initial parasagittal tomographic image of a dentate patient. Figure 2(B) Is the tomographic image of the paranasal sinuses in which the largest. Length of the genital canal (L or L1). Figure 2(C) is the parasagittal tomographic image in which the largest. The diameter of the genital plexus (W or D). Figure 2(D) is the tomographic image in which the measurement of the shortest distance from the plexus to alveolar bone crest (D1 or L2), shorter distance from the plexus to the buccal cortex (D2 or L3), and less distance from the plexus to the base of the mandible (D3 or L4).

Figure 3(A) is the initial parasagittal tomographic image of an edentulous patient. Figure 3(B) is the parasagittal tomographic image in which the largest length of the genital canal (L or L1) was measured. Figure $3(C)$ is the parasagittal tomographic image in which the largest diameter of the genital plexus (W or D) was measured. Figure $3(\mathrm{D})$ is the tomographic image in which the lowest distance from the genital plexus to the alveolar bone crest (D1 or L2) was measured; in this case, as the foramen, this surface was zero; shorter distance from the plexus to the cortical buccal (D2 or L3); and shorter distance from the plexus to the base of the mandible (D3 or L4).

\section{Statistical Analysis}

In the evaluation of dental presence, the basic assumptions of normality and homogeneity of variance of the sample were not met, thus the non-parametric Mann-Whitney test was used. For the sex variable, the data had a normal distribution, thus the Student's t-test was applied.

As for age, the assumptions of normality and homogeneity were also not met, thus the Kruskal-Wallis and Dunn tests were applied. 

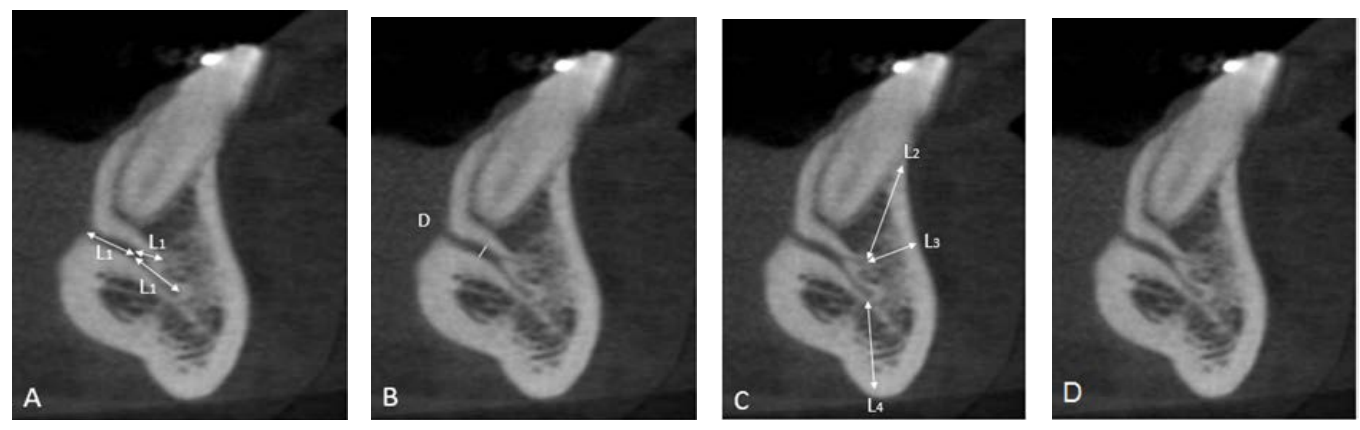

Figure 1. Tomographic images, diameters and distances of the canal and plexus. (A) Parasagittal tomographic image; (B) Canal diameter; (C) Distance from the genial plexus to the cortical bone; (D) Initial parasagittal tomographic image, central incisor tooth. Source: Own Authorship. Caption: Parasagittal tomographic image measuring the length (A) canal diameter (B) and distances as follows: $\left(\mathrm{L}_{1}\right)$ of the genial canal; $\left(\mathrm{L}_{2}\right)$ distance from the genial plexus to the alveolar bone crest, $\left(\mathrm{L}_{3}\right)$ distance from the genial plexus to the buccal cortical bone and the base of the mandible $\left(\mathrm{L}_{4}\right)(\mathrm{C})$, initial parasagittal tomographic image (D). Figure 1 (A) Parasagittal section of the CBCT used to perform measurements. (B) Longest width of the genial canal (W). (C) longest length of the genial canal (L). (D) Shortest distance from the genial plexus to the alveolar bone crest (D1); shortest distance from the genial plexus to the buccal cortical bone (D2); shortest distance from the genial canal relative to the base of the mandible (D3).

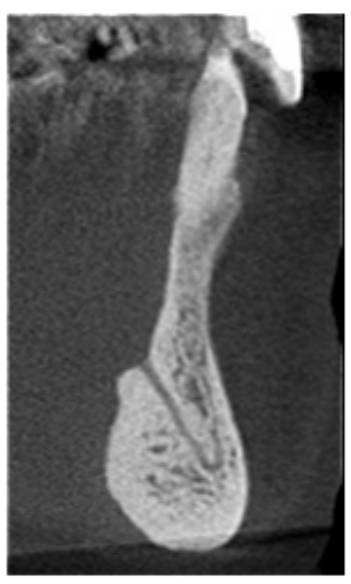

(A)

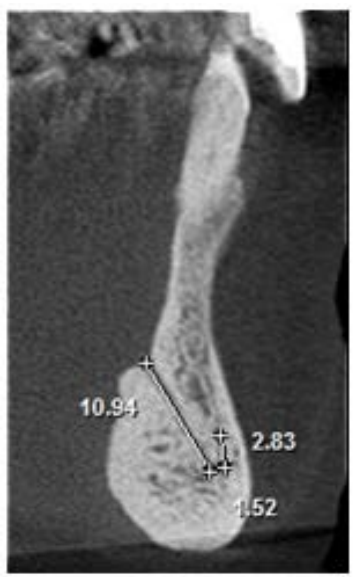

(B)

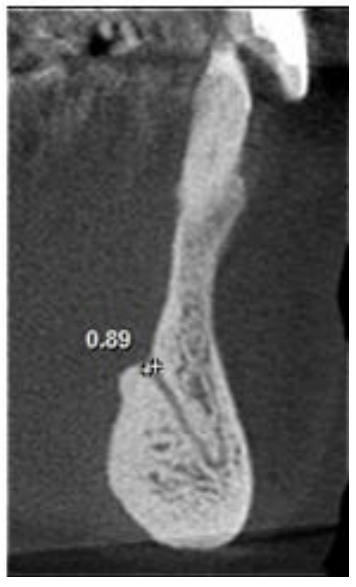

(C)

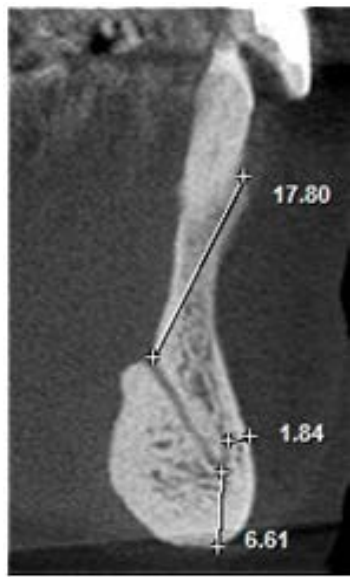

(D)

Figure 2. Patient case study. (A) Original parasagittal cut; (B) Measurement of length; (C) Diameter measurement; (D) They will measure the distance from the plexus to the bony crest, from the plexus to the from the plexus to the mandibular base. Source: Own Authorship.

For statistical calculations, the SPSS 23 program (SPSS INC., Chicago, IL, USA) was used, adopting the significance level of $5 \%$.

\section{RESULTS}

Of the 149 CBCT exams evaluated, 59 (39.6\%) were male and 90 (60.4\%) were female. The patients' ages ranged from 18 to 86 years old, with an average of $52.2 \pm 15.7$ years. Among edentulous patients, the ages ranged from 38 to 86 years, mean age was 62.6 years, with a standard deviation of 1.1 years. Among 


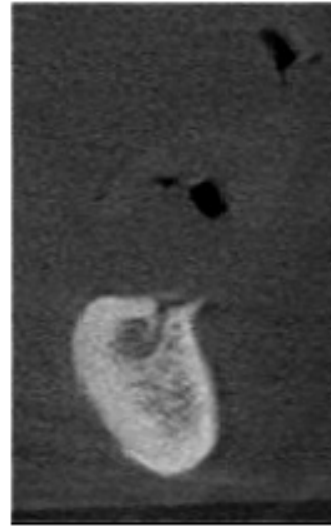

(A)

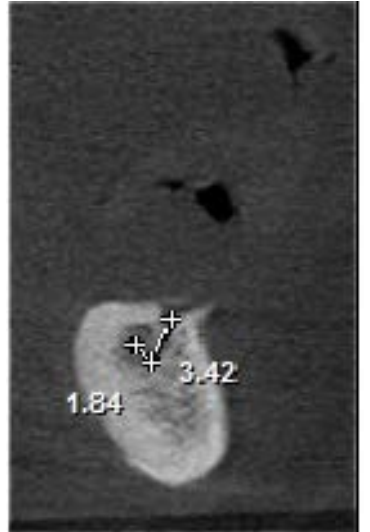

(B)

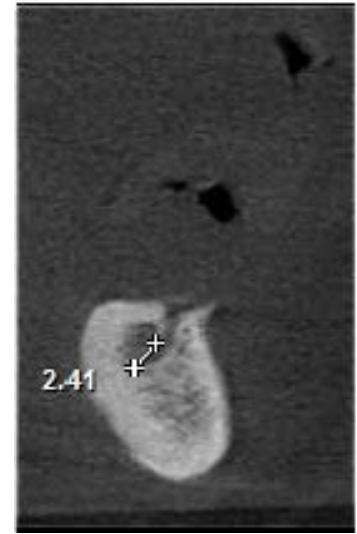

(C)

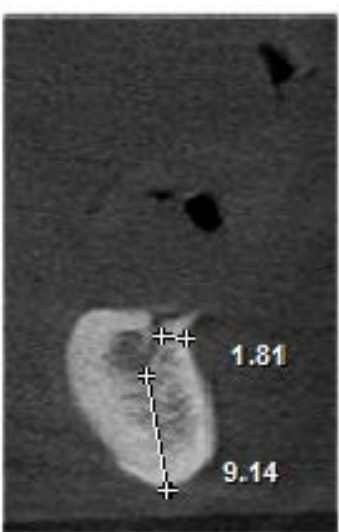

(D)

Figure 3. Edentulous patient case. (A) Original parasagittal cut; (B) Channel length measurement; (C) Channel diameter measurement; (D) Measurement of distance from the plexus to the buccal cortical, the base of the mandible and the bone crest. Source: Own Authorshi.

the toothed teeth, the age ranged from 18 to 70 years, the mean being 41.8 years and the standard deviation of 1.5 years.

Of the 74 patients in the dentate group, 36 (48.64\%) belonged to the male group, and $38(51.35 \%)$ belonged to the female group. Of the total of 75 patients in the edentulous group, 23 (30.66\%) belong to the male group and 52 (69.33\%) belong to the female group.

Considering the presence or absence of teeth, the length of the genial canal and the distances of the plexus in relation to the alveolar crest and the buccal cortical bone, dentate patients showed significantly higher values. The width of the genial canal and distance from the base of the mandible were similar between the edentulous and dentate groups (Table 2).

Of the total of 59 male patients, 36 (61.01\%) belong to the dentate group, and 23 (38.98\%) belong to the edentulous group, presenting a mean age of 50.81 years for the male group. Of the total of 90 female patients, $38(42.22 \%)$ belong to the dentate group and $52(57.77 \%)$ belong to the edentulous group, presenting a mean age of 55.63 years for the female group.

Regarding the sex of the patients, the distances of the genial plexus in relation to the alveolar crest and the buccal cortical bone showed significantly higher values for the male sex (Table 3).

Of the 21 patients aged up to 30 years, $11(52.38 \%)$ were male and $10(47.61 \%)$ were female. Of the 78 patients aged 31 to 60 years, $32(41.02 \%)$ were males and $46(58.97 \%)$ were females. Of the total of 50 patients aged 61 or over, $15(30.00 \%)$ are males and $35(70.00 \%)$ are females. Of the total of 75 edentulous patients, $0(0 \%)$ are aged up to 30 years, $32(42.66 \%)$ are between 31 and 60 years of age, and $43(57.33 \%)$ are 61 years of age or older. Of the 74 toothed patients, $21(28.37 \%)$ were aged up to 30 years, $45(60.81 \%)$ were between 31 and 60 years of age and 7 (9.45\%) were 61 years of age or older.

Considering the age of the patients, it was observed that only the distance from the genial plexus to the alveolar crest presented a statistically significant difference in relation to age. The shortest distance from the genial plexus to the alveolar crest was found in the more advanced age group ( $\geq 61$ years), which was 4.4 and 3.2 times shorter than that observed in individuals until 30 years and between 31 and 60 years, respectively (Table 4).

\section{ANALYSIS OF RESULTS}

In the present study, it was possible to locate and measure the genial plexus in all patients in the sample $(\mathrm{n}=149)$ using the CBCT. Likewise, a mandibular incisive canal (MIC) was identified in 100\% of CBCT images, with good clarity in $63.6 \%$ in the work of [26]. They stated that CBCT is particularly suitable for 
Table 2. Means and standard deviations $(\mathrm{mm})$ of the width, length and distances of the genial plexus in relation to the presence or absence of teeth.

\begin{tabular}{lccc}
\hline & Edentulous $(\mathrm{n}=75)$ & Dentate $(\mathrm{n}=74)$ & Value of $\mathrm{p}$ \\
\hline Width (W) & $1.24 \pm 0.41$ & $1.24 \pm 0.62$ & $\mathrm{p}=0.564$ \\
Length (L) & $7.81 \pm 2.05$ & $8.19 \pm 2.41$ & $\mathrm{p}=0.030^{*}$ \\
Distance to alveolar crest (D1) & $4.45 \pm 5.61$ & $17.48 \pm 3.02$ & $\mathrm{p}<0.001^{*}$ \\
Distance to buccal cortical bone (D2) & $2.51 \pm 1.58$ & $3.41 \pm 1.55$ & $\mathrm{p}<0.001^{*}$ \\
Distance to the base of the mandible (D3) & $3.39 \pm 2.36$ & $3.82 \pm 2.11$ & $\mathrm{p}=0.133$ \\
\hline
\end{tabular}

Source Author: Statistically different values by the Mann-Whitney test $(\mathrm{p} \leq 0.05)$.

Table 3. Means and standard deviations $(\mathrm{mm})$ of the width, length and distances of the genial plexus in relation to sex.

\begin{tabular}{lccc}
\hline & Male $(\mathrm{n}=59)$ & Female $(\mathrm{n}=90)$ & Value of $\mathrm{p}$ \\
\hline Width (W) & $1.23 \pm 0.36$ & $1.25 \pm 0.61$ & $\mathrm{p}=0.817$ \\
Length (L) & $8.25 \pm 2.51$ & $7.83 \pm 2.04$ & $\mathrm{p}=0.259$ \\
Distance to alveolar crest (D1) & $14.04 \pm 7.12$ & $8.88 \pm 7.81$ & $\mathrm{p}<0.001^{*}$ \\
Distance to buccal cortical bone (D2) & $3.31 \pm 1.68$ & $2.72 \pm 1.55$ & $\mathrm{p}=0.028^{*}$ \\
Distance to the base of the mandible (D3) & $4.02 \pm 2.36$ & $3.33 \pm 2.13$ & $\mathrm{p}=0.065$ \\
\hline
\end{tabular}

Source: Statistically different values by the student's t-test $(\mathrm{p} \leq 0.05)$.

Table 4. Means and standard deviations $(\mathrm{mm})$ of the width, length and distances of the genial plexus in relation to age.

\begin{tabular}{lcccc}
\hline & $\leq 30$ years & 31 to 60 years & $\geq 61$ years & Value of $\mathrm{p}$ \\
\hline Width (W) & $1.17 \pm 0.40$ & $1.25 \pm 0.61$ & $1.26 \pm 0.42$ & $\mathrm{p}=0.793$ \\
Length (L) & $8.11 \pm 2.44$ & $7.94 \pm 2.11$ & $8.04 \pm 2.39$ & $\mathrm{p}=0.940$ \\
Distance to alveolar crest (D1) & $17.96 \pm 3.38$ & $12.99 \pm 7.11$ & $4.04 \pm 5.97$ & $\mathrm{p}<0.001^{*}$ \\
Distance to buccal cortical bone (D2) & $3.00 \pm 1.65$ & $3.21 \pm 1.53$ & $2.50 \pm 1.69$ & $\mathrm{p}=0.052$ \\
Distance to the base of the mandible (D3) & $3.82 \pm 2.13$ & $3.44 \pm 2.23$ & $3.78 \pm 2.33$ & $\mathrm{p}=0.641$ \\
\hline
\end{tabular}

Source Author: Statistically different values by the Kruskal-Wallis test ( $\mathrm{p} \leq 0.05)$.

the mandible since it enables the 3D reconstruction of high-resolution images of the entire mandible [26] because conventional radiographs often fail to show an incisive canal. [27]

There was no significant difference $(\mathrm{p}$ value $=0.564$ ) between the diameter of the genial plexus in edentulous and dentate patients, the mean value in both groups being $1.24 \pm 0.41 \mathrm{~mm}$ and $1.24 \pm 0.61 \mathrm{~mm}$, respectively. Similar results were found by [28] (mean $1.3 \mathrm{~mm}$, range $0.5-2 \mathrm{~mm}$ at the entrance of the incisive canal) [11] and (mean $1.48 \pm 0.66 \mathrm{~mm}$ ) with no difference in the diameter of the incisive bundle 
between a dentate and edentulous group. However, reported a mean diameter of $1.8 \pm 0.5 \mathrm{~mm}$ for this canal [27]. A spiral CT scan study presented a larger buccal diameter of the bony canal in dentate mandibles, although the authors considered the number of edentulous patients as limited [6]. Failure of osseointegration of implants in case of perforation of a mandibular incisive canal having a diameter of $>2$ $\mathrm{mm}$, due to soft tissue migration along the implant has been reported [14].

Other data obtained was the average length of the genial canals, which showed that the values for edentulous patients were statistically lower than in dentate patients. This data suggest that bone remodeling caused by dental absence may lead to decreased blood vessel length, possibly due to a reduced need for blood supply, since the volume of the intraosseous space and the area of the vestibular gingiva in the region are smaller, and also, due to the absence of teeth to be nourished, with such functions being of the genial plexus $[7,8]$.

There was no significant difference in the values referring to the distance from the plexus to the mandibular base when comparing both groups, $3.82 \mathrm{~mm}$ for dentate individuals and $3.39 \mathrm{~mm}$ for edentulous individuals. These findings are in line with the studies [24] of (on average $7.2 \mathrm{~mm}$ in the incisor region) [6] and (on average $7.40(5.31) \mathrm{mm}$ from the mandibular base at the lingual entrance and $7.96(3.47) \mathrm{mm}$ at the buccal canal end point) [29] reported that all measurements were made at basal bone (where the MIC is located), which undergoes less resorption as compared to the alveolar bone and they believed that the measurements obtained were consistent, regardless of the patients being dentate or edentulous. This data suggests that the clinician should ideally decide the safety margin for graft removal not only by relying on the mean safety margin but also after evaluating a CBCT examination.

New safety margins for bone graft block removal from the chin region were suggested by [30] $8 \mathrm{~mm}$ below the apex of the involved teeth and $4 \mathrm{~mm}$ deep for Caucasians, since the mandibular incisor canal is at least $4.65 \mathrm{~mm}$ from the buccal cortical bone. However, this data is refuted by the data collected in this study in the midline region because the distance from the genial canals to the buccal cortical bone was 2.51 $\mathrm{mm}$ for edentulous patients and $3.41 \mathrm{~mm}$ for dentate patients. This data is similar to the values found by Al-Ani et al. (2013) (3.15 mm) and by [31] (3.41), suggesting that the midline region should be avoided during the removal of bone grafts from the ment.

The distance from the genial plexus to the alveolar bone crest was statistically shorter $(\mathrm{p}=0.001)$ in edentulous patients compared to dentate patients, $4.45 \mathrm{~mm}$ and $17.48 \mathrm{~mm}$ respectively, which indicates that bone remodeling post-extraction makes this anatomical structure more superficial, being more subject to surgical trauma and postoperative complications such as hemorrhage and paraesthesia in this region. In view of the values for edentulous patients, the midline should be avoided during implant installation in order to avoid such complications. The study by [26] reinforces the findings regarding toothed patients, as it found a value of $16.23 \mathrm{~mm}$, similar in relation to the mean distance of the MIC to the alveolar bone crest.

Considering the measures performed, when comparing them between the sexes, only the distance between the genial plexus and the buccal cortical bone beyond the alveolar bone crest, presented a statistically significant difference, and the values were substantially lower for women. In the female group, the mean distance between the alveolar bone crest and the genial plexus was $8.88 \mathrm{~mm}$, considering the distance between the buccal cortical bone and the genial plexus, the mean value obtained was $2.72 \mathrm{~mm}$, indicating a higher surgical risk for this group, in interventions in this region.

Analyzing the measurements and comparing them between the different age groups, it was verified that only the distance between the genial plexus and the alveolar bone crest presented a discrepancy. As age advances, distance decreases, starting with mean values of $17.96 \mathrm{~mm}$ in the age group of up to 30 years and reaching $4.04 \mathrm{~mm}$ in the age group of 61 years or more, which indicates that the higher the age of the patient the higher the chance of not being able to install dental implants in this region.

For the retrospective design in which the present study was carried out, it is possible to observe the limitation of not being possible to identify the race of the patients of the sample, as well as the correlation of stature and weight with the data found, and these factors can influence the results. It is still notable that there are other factors capable of interfering with the result of this work, such as the fact that the basic as- 
sumptions of normality and homogeneity of variance of the sample regarding age and sex were not met.

\section{CONCLUSIONS}

In order for the planning of surgical procedures in the mandibular midline region to be accurate, one should measure the extension and evaluate the three-dimensional location of the genial plexus, taking into account factors that directly influence such data as the patient's sex, age and dental presence. The females present a shorter distance from the plexus to the crest and to the buccal cortical bone. Older patients have a shorter distance from the plexus to the crest. In the case of edentulous patients, the distance from the plexus to the alveolar crest and the buccal cortical bone is shorter.

Neurosensory dysfunctions, hemorrhage and pain are possible complications linked to injury of the genial plexus and observance of the variables of this study at the preoperative stage is fundamental so that it can be avoided either during the removal of bone grafts or in implant installation surgeries, a region commonly approached in protocol type surgeries, and it is interesting to avoid this region mainly in edentulous patients.

In order to better understand the effects of the variables of this research on the dimensions and three-dimensional location of the genial plexus, as well as the influence that the variables exert on each other, and if there are other factors that influence the dimensions and location of the genial plexus, more studies evaluating different groups and other possible variables would be of great value.

\section{REFERENCES}

1. Benninger, B., Miller, D., Maharathi, A. and Carter, W. (2011) Dental Implant Placement Investigation: Is the Anterior Loop of the Mental Nerve Clinically Relevant? Journal of Oral and Maxillofacial Surgery, 69, 182-185. https://doi.org/10.1016/j.joms.2010.07.060

2. Greenstein, G. and Tarnow, D. (2006) The Mental Foramen and Nerve: Clinical and Anatomical Factors Related to Dental Implant Placement: A Literature Review. Journal of Periodontology, 77, 1933-1943. https://doi.org/10.1902/jop.2006.060197

3. Jacobs, R., Lambrichts, I., Liang, X., Martens, W., Mraiwa, N., Adriaensens, P. and Gelan, J. (2007) Neurovascularization of the Anterior Jaw Bones Revisited Using High-Resolution Magnetic Resonance Imaging. Oral Surgery, Oral Medicine, Oral Pathology, Oral Radiology, and Endodontology, 103, 683-693. https://doi.org/10.1016/j.tripleo.2006.11.014

4. Rosano, G., Taschieri, S., Gaudy, J.F., Testori, T. and Del Fabbro, M. (2009) Anatomic Assessment of the Anterior Mandible and Relative Hemorrhage Risk in Implant Dentistry: A Cadaveric Study. Clinical Oral Implants Research, 20, 791-795. https://doi.org/10.1111/j.1600-0501.2009.01713.x

5. Liang, X., Jacobs, R., Lambrichts, I. and Vandewalle, G. (2007) Lingual Foramina on the Mandibular Midline Revisited: A Macroanatomical Study. Clinical Anatomy, 20, 246-251. https://doi.org/10.1002/ca.20357

6. Liang, X., Jacobs, R. and Lambrichts, I. (2006) An Assessment on Spiral CT Scan of the Superior and Inferior Genial Spinal Foramina and Canals. Surgical and Radiologic Anatomy, 28, 98-104. https://doi.org/10.1007/s00276-005-0055-y

7. Krasny, A., Krasny, N. and Prescher, A. (2012) Study of inferior Dental Canal and Its Contents Using High-Resolution Magnetic Resonance Imaging. Surgical and Radiologic Anatomy, 34, 687-693. https://doi.org/10.1007/s00276-011-0910-y

8. Monsour, P.A. and Dudhia, R. (2008) Implant Radiography and Radiology. Australian Dental Journal, 53, S11-S25. https://doi.org/10.1111/j.1834-7819.2008.00037.x

9. Jacobs, R., Mraiwa, N., van Steenberghe, D., Gijbels, F. and Quirynen, M. (2002) Appearance, Location, Course, and Morphology of the Mandibular Incisive Canal: An Assessment on Spiral CT Scan. Dentomaxillofacial Radiology, 31, 322-327. https://doi.org/10.1038/sj.dmfr.4600719 
10. Wadu, S.G., Penhall, B. and Townsend, G.C. (1997) Morphological Variability of the Human Inferior Alveolar Nerve. Clinical Anatomy, 10, 82-87. https://doi.org/10.1002/(SICI)1098-2353(1997)10:2<82::AID-CA2>3.0.CO;2-V

11. Rosa, M.B., Sotto Maior, B.S., Machado Vde, C. and Francischone, C.E. (2013) Retrospective Study of the Anterior Loop of the Inferior Alveolar Nerve and the Incisive Canal Using Cone Beam Computed Tomography. The International Journal of Oral \& Maxillofacial Implants, 28, 388-392. https://doi.org/10.11607/jomi.2648

12. Liang, X., Jacobs, R., Lambrichts, I., Vandewalle, G., van Oostveldt, D., Schepers, E., et al. (2005) Microanatomical and Histological Assessment of the Content of Superior Genial Spinal Foramen and Its Bony Canal. Dentomaxillofacial Radiology, 34, 362-368. https://doi.org/10.1259/dmfr/75895125

13. Mraiwa, N., Jacobs, R., van Steenberghe, D. and Quirynen, M. (2003) Clinical Assessment and Surgical Implications of Anatomic Challenges in the Anterior Mandible. Clinical Implant Dentistry and Related Research, No. 5, 219-225. https://doi.org/10.1111/j.1708-8208.2003.tb00204.x

14. Rosenquist, B. (1996) Is There an Anterior Loop of the Inferior Alveolar Nerve? The International Journal of Periodontics and Restorative Dentistry, 16, 40-45.

15. Abarca, M., Van, S.D., Malevez, C., De, R.J. and Jacobs, R. (2006) Neurosensory Disturbances after Immediate Loading of Implants in the Anterior Mandible: An Initial Questionnaire Approach Followed by a Psychophysical Assessment. Clinical Oral Investigations, No. 4, 269-277. https://doi.org/10.1007/s00784-006-0065-0

16. Chaushu, G., Taicher, S., Halamish-Shani, T. and Givol, N. (2002) Medicolegal Aspects of Altered Sensation Following Implant Placement in the Mandible. The International Journal of Oral \& Maxillofacial Implants, No. 4, 413-415.

17. Mason, M.E., Triplett, R.G. and Alfonso, W.F. (1990) Life-Threatening Hemorrhage from Placement of a Dental Implant. Journal of Oral and Maxillofacial Surgery, 48, 201-204. https://doi.org/10.1016/S0278-2391(10)80211-3

18. McDonnell, D., Reza Nouri, M. and Todd, M.E. (1994) The Mandibular Lingual Foramen: A Consistent Arterial Foramen in the Middle of the Mandible. Journal of Anatomy, 184, 363-369.

19. Howe, G.L. and Poyton, H.G. (1960) Prevention of Damage to the Inferior Dental Nerve during the Extraction of Mandibular Third Molars. British Dental Journal, 109, 355-363.

20. Howard, H., Mc Quire, T. and Giolious, P. (2004) Inferior Alveolar Nerve Damage during Removal of Mandibular Third Molars. Oral Health Group, Toronto.

21. Haghanifar, S. and PoorsattarBejeh Mir, A. (2015) Accessory Mental Foramina, Incisive Nerve Plexus and Lingual Canals with Unusual Emergence Paths: Report of Two Rare Cases. Indian Journal of Dentistry, 6, 44-48. https://doi.org/10.4103/0975-962X.151710

22. Cavalcanti, M. (2010) Tomografia computadorizada por feixe cônico interpretação e diagnostico para o cirurgião dentista. [Cone-Beam Computed Tomography Interpretation and Diagnosis for the Dentist Surgeon.] Santos, São Paulo, 27-77.

23. Loubele, M., Jacobs, R., White, S.C., Maes, F., Denis, K., Lambrichts, I., et al. (2006) Accuracy of Linear Measurements on the Lower Jaw in CBCT Based on a Ground-Truth Acquired with Laser Scanning: Preliminary Results. 10th European Congress of Dento Maxillofacial Radiology, Leuven.

24. Naitoh, M., Katsumata, A., Kubota, Y., Okumura, S., Hayashi, H. and Ariji, E. (2006) The Role of Objective Plane Angulation on the Mandibular Image Using Cross-Sectional Tomography. Journal of Oral Implantology, 32, 117-121. https://doi.org/10.1563/803.1

25. Uchida, Y., Noguchi, N., Goto, M., Yamashita, Y., Hanihara, T., Takamori, H., et al. (2009) Measurement of Anterior Loop Length for the Mandibular Canal and Diameter of the Mandibular Incisive Canal to Avoid Nerve Damage When Installing Endosseous Implants in the Interforaminal Region: A Second Attempt Introducing 
Cone Beam Computed Tomography. Journal of Oral and Maxillofacial Surgery, 67, 744-750.

https://doi.org/10.1016/j.joms.2008.05.352

26. Kong, N., Hui, M., Miao, F., Yuan, H., Du, Y. and Chen, N. (2016) Mandibular Incisive Canal in Han Chinese Using Cone Beam Computed Tomography. International Journal of Oral and Maxillofacial Surgery, 45, 1142-1146. https://doi.org/10.1016/j.ijom.2016.04.019

27. Mardinger, O., Chaushu, G., Arensburg, B., Taicher, S. and Kaffe, I. (2000) Anatomic and Radiologic Course of the Mandibular Incisive Canal. Surgical and Radiologic Anatomy, 22, 157-161. https://doi.org/10.1007/s00276-000-0157-5

28. Bavitz, J.B., Harn, S.D., Hansen, C.A. and Lang, M. (1993) An Anatomical Study of Mental Neurovascular Bundle-Implant Relationships. The International Journal of Oral \& Maxillofacial Implants, 8, 563-567.

29. Al-Ani, O., Nambiar, P., Ha, K.O. and Ngeow, W.C. (2013) Safe Zone for Bone Harvesting from the Interforaminal Region of the Mandible. Clinical Oral Implants Research, 24, 115-121. https://doi.org/10.1111/j.1600-0501.2011.02393.x

30. Pommer, B., Tepper, G., Gahleitner, A., Zechner, W. and Watzek, G. (2008) New Safety Margins for Chin Bone Harvesting Based on the Course of the Mandibular Incisive Canal in CT. Clinical Oral Implants Research, 19, 1312-1316. https://doi.org/10.1111/j.1600-0501.2008.01590.x

31. Vu, D.D., Brockhoff, H.C., Yates, D.M., Finn, R. and Phillips, C. (2015) Course of the Mandibular Incisive Canal and Its Impact on Harvesting Symphysis Bone Grafts. Journal of Oral and Maxillofacial Surgery, 73, 258.e1-e12. https://doi.org/10.1016/j.joms.2014.10.005 